\title{
Serving Their Needs: A Qualitative Examination of Nutrition Policy Implementation in the Early Care and Education Setting
}

\author{
Caree J. Cotwright, PhD, RDN, LD ${ }^{1}$, Jori Hall, $\mathrm{PhD}^{2}$, Nicole M. Arrington, $\mathrm{MPH}^{3}$, Nathalie Celestin, MPH, CHES ${ }^{3}$, Hayley \\ Sanders ${ }^{5}$, Taylor Ragan ${ }^{5}$, Sarah Stotz, PhD, MS, RD ${ }^{6}$, and Leann Birch, $\mathrm{PhD}^{7}$

\begin{abstract}
${ }^{1}$ Assistant Professor, The University of Georgia, ${ }^{2}$ Associate Professor, The University of Georgia, ${ }^{3}$ Under the Shade Tree, LLC, ${ }^{4}$ Research Coordinator, The University of Georgia, ${ }^{5}$ Graduate Research Assistant, The University of Georgia, ${ }^{6}$ Senior Instructor, Centers for American Indian and Alaska Native Health, Colorado School of Public Health, University of Colorado Anschutz Medical Campus, and ${ }^{7}$ Professor, The University of Georgia (Deceased, Died May 26, 2019)
\end{abstract}

Corresponding Author: Caree J. Cotwright, PhD, RDN, LD • Assistant Professor, The University of Georgia • 280 Dawson Hall, Athens, GA 30602 • Telephone: (706) 542-3073•Email: cjcot@uga.edu

\section{ABSTRACT}

Background: Childhood obesity is a growing problem in the United States and results in increased risk for chronic diseases such as diabetes, heart disease, and hypertension. Thirteen percent of youth in Georgia are obese. Identifying strategies to assist children in establishing healthy habits is essential to reduce the risk of childhood obesity. The Early Care and Education (ECE) setting is ideal for the implementation of obesity prevention practices. However, there are barriers present for implementing nutrition policies in this setting. This report explores the implementation of food and beverage best practices in the ECE setting and highlights barriers to and facilitators for adopting these policies.

Methods: We conducted 24 interviews and 6 focus groups with ECE program directors and teachers in 6 regions in Georgia. The statewide sample included directors from child care learning centers, family child care homes, and license-exempt programs. A trained qualitative researcher facilitated focus groups and interviews. Data were audio recorded and transcribed verbatim. Qualitative data analysis software, NVivo 10, was used to code data and identify emergent themes.

Results: Several key themes related to barriers to food and beverage policy implementation emerged including the need for: 1) enhanced parent communication, 2) resources to limit juice consumption, and 3) financial support to decrease food costs. Facilitators of nutrition policy implementation included: 1) ease of access to water, 2) children's preferences for fruits and vegetables, and 3) availability of existing nutrition resources. Findings will inform the development of resources to support nutrition policy implementation as well as policy training for ECE teachers in Georgia.

Conclusions: Study themes may provide insight about how to improve current resources and develop new solutions to improve adoption and implementation of nutrition policies in the ECE setting in the future.

Keywords: Qualitative research, early care and education teachers, obesity prevention, nutrition, policy, statewide, Georgia

\section{INTRODUCTION}

Childhood obesity is a growing problem globally, but more particularly, in the United States (Ickes et al., 2014). The rates of obesity have been increasing among children throughout different periods between the late 1970s until the 2000s, regardless of race, age, ethnicity, or gender (Bethell et al., 2009). However, minorities, including African-Americans, American Indians, and Alaskan Natives, and Hispanics are more likely to be overweight or obese compared to those that are non-Hispanic whites (Hales et al., 2017). These rates are increasing more in developed countries and urbanized areas (Ickes et al., 2014). In the United States, these rates tend to be higher and have more than tripled from 1980 to 2010 (Ickes et al., 2014).
According to the National Health and Nutrition Examination Survey (NHANES), the rates of obesity among 2-to-5-year-old children were $10.1 \%$ between 2007 and 2008, and rose to $13.9 \%$ in 2015-2016 (Hales et al., 2018). About $25 \%$ of children under five years of age in the United States are above the 85th percentile for Body Mass Index (BMI), which indicates that these children are overweight or obese (Nayak et al., 2018). In Georgia, the obesity rate as of 2014 among 2- to 4-year old low-income children was 13\% (RWJF, 2019).

Many factors can contribute to childhood obesity, including lack of adequate nutrition, overconsumption of empty calories, minimal physical activity, environmental factors, and genetics (Vall et al., 2017). Childhood obesity can cause 
many different adverse health outcomes, including increased blood pressure and elevated cholesterol, both of which lead to an increased risk for cardiovascular disease later on in life (Ickes et al., 2014). Children with obesity also have a higher risk of developing type 2 diabetes due to insulin resistance and glucose intolerance (Ickes et al., 2014). Also, various psychological aspects can impact a child who is overweight or obese, including stigmatization, negative stereotyping, and bullying (Budd and Hayman, 2006).

The evidence-based Dietary Guidelines for Americans (DGA) 2015-2020, are recommendations for people aged two years and older to help "promote health, prevent chronic disease, and help people reach and maintain a healthy weight" (U.S. Department of Health and Human Services, 2015). The DGAs are updated every five years to remain current with new research and recommendations (U.S. Department of Health and Human Services, 2015). Most children are not consuming a healthy diet in line with the DGAs. On average, they are consuming too many high-fat foods and sugar-sweetened beverages and low amounts of fruits and vegetables (Witt and Dunn, 2012). The fruits and vegetables most frequently consumed are fruit juice and potatoes, and french fries make up almost $25 \%$ of vegetable consumption (Witt and Dunn, 2017). Around $44 \%$ of children from 2 to 5 years of age consume at least one sugar-sweetened beverage or fruit drink per day (Lott et al., 2019). When children attend care outside of the home, studies have shown that there is low consumption of vegetables and whole grains and high consumption of fruit juice, high-fat foods, and sweet or salty foods among children (Nayak et al., 2018).

The early care and education (ECE) setting is an ideal venue for childhood obesity prevention. Around $75 \%$ of children ages three to five are in some form of care outside of the home (Nayak et al., 2018). Many of these children spend most of their day in this setting (Natale et al., 2014). Children consume at least $50 \%$ of their recommended dietary allowance of calories while in ECE, which is another opportunity to influence much of what they are eating (Nayak et al., 2018). The ECE setting, therefore, provides a captive audience that can be impacted by teachers acting as role models for healthy behaviors, modeling by other children, and nutrition education.

In Georgia, there are three main types of ECE facilities. Programs include, child care learning centers (serving seven or more children), family child care homes (serving six or less children), and license-exempt facilities (programs that operate legally without a license such as faith-based programs) (Georgia Department of Early Care and Learning). Foods and beverages provided by ECE centers (not homes and license-exempt programs) in Georgia must meet standards required by the United States Department of Agriculture (USDA) Child and Adult Care Food Program (CACFP). As a federal program that helps to promote nutritious meals and snacks in the ECE setting, CACFP requires meals to meet specific standards for reimbursement (USDA, 2016). Compensation for CACFP is dependent on the income of parents and is primarily used for programs serving low-income families (USDA, 2016). CACFP guidelines were updated in April 2016 for the first time since the creation of the program (USDA, 2016.) Updates to standards included the provision of more protein options, whole grains, foods with less added sugar, more variety in fruits and vegetables served, and limitations on the amount of $100 \%$ juice served. (USDA, 2016). These requirements, which went into effect for ECE programs in October 2017, help to provide well-balanced meals to promote healthier foods that are served by ECE programs.

Young children are completely reliant on adults for their nutritional needs in the ECE setting, which allows ECE teachers to play a vital role in what children consume (Natale et al., 2014). In early childhood, children have the opportunity to establish healthy habits. Teachers act as role models for these healthy lifestyle behaviors for their students, such as consuming fruits and vegetables (Natale et al., 2014). Children also need to understand their internal cues to help them recognize feelings of hunger and fullness (Dev et al., 2016). Best practices for ECE teachers to implement during mealtime include allowing the children to determine how much they will eat, gently encouraging trying new foods through modeling healthy eating, and repeatedly exposing children to new foods (Dev et al., 2016).

ECE teachers experience several barriers to implementing classroom interventions, such as classroom management, lack of time to teach a wide-range topics, lack of resources, and low-self-efficacy to teach new topics (Zhai and Li-Grining, 2011). Adequate teacher training and coaching can increase teachers' self-efficacy to implement classroom-based interventions (Zhai and Li-Grining, 2011). Barriers to implementing healthy food and beverage policies can include lack of support from individuals that can impact policy implementation, lack of space to implement specific changes, health and safety concerns, and competing expectations regarding the adoption of policies (Cotwright et al., 2017). Facilitators to implementing these policies can include written guidelines and the supply of materials needed to implement strategies in the classroom (Cotwright et al., 2017).

Qualitative research can help explain the how and why of behavior or outcomes (Swift and Tischler, 2010). Qualitative research can also help elicit an understanding of specific aspects of an intervention to better develop concepts (Swift and Tischler, 2010). This understanding is essential for several reasons, including investigating causes for effectiveness or ineffectiveness of the intervention, factors that impact intervention implementation, and explaining experiences of those receiving the intervention (Swift and Tischler, 2010). 
The current qualitative study was a part of a mixed-methods design (Creswell, 2003), which included a statewide quantitative survey using a modified version of the California Survey of 0-5-Year-Old Children (Ritchie et al., 2012). The survey assessed foods and beverages served in ECE programs and included questions related to barriers and facilitators to the implementation of food and beverage best practices and policies. The study sample included licensed and license-exempt child care programs in Georgia serving children aged 0-5 years. Sixty-seven percent of the ECE programs participated in CACFP (Cotwright, 2019). Quantitative findings from the survey results have been reported elsewhere (Cotwright, 2019). Outcomes suggest that programs participating in CACFP were less likely to serve sugar-sweetened beverages (SSBs) and more likely to provide low-fat or fat-free milk for 2- to 5-year old children than non-CACFP programs (Cotwright, 2019). However, all program types had low compliance with implementing water policies. The purpose of this study was to further explore the knowledge gaps related to identified barriers to and facilitators of the adoption of healthy food and beverage policies in the ECE setting in Georgia.

\section{METHODS}

Qualitative information is vital to understand the perspectives of individuals and groups and further explore factors that contribute to an outcome (Patton, 2015). The University of Georgia Institutional Review Board approved the study before the start of data collection and classified it as exempt.

\section{Data Collection}

Data collection included in-person individual interviews and focus groups in six regions throughout Georgia based on Child Care Resource and Referral Agency classifications (Northwest -1, Central West-2, Central East-3, Southwest-4, Southeast-5, and Northeast-6). Moderator guides for both individual and focus group interviews were developed based on an analysis of quantitative survey findings. A trained qualitative researcher conducted focus group interviews with one note taker present. All participants worked in ECE programs in the state of Georgia and received a $\$ 15$ gift card for their participation. Interviews were audio-recorded and transcribed.

\section{Individual interviews}

Twenty-four semi-structured individual interviews were conducted with ECE center directors $(n=16)$, family child care home directors $(n=4)$, and license-exempt ECE program directors $(n=4)$. Interviews provided understanding about the implementation of healthy food and beverage policies from the perspective of those who oversee ECE programs and teach children. During the interviews, to ensure that participants were aware of the newly revised CACFP policies, directors were provided with CACFP fact sheets that outlined updates to the healthy food and beverage guidelines. Providing these documents allowed participants to recall the specifics of the CACFP, including the new revisions, and reflect on their experiences with the policy. Topics covered during director interviews included exploring existing policies implemented at ECE programs, supports for and challenges to promoting healthy habits in their ECE programs, as well as resources needed for and recommendations to implement nutrition recommendations. Interviews were conducted at the director's respective ECE program location and lasted approximately 60 minutes.

\section{Focus group interviews}

Six focus groups with ECE center teachers were conducted to gain an understanding of policy implementation from the perspective of teachers. Each focus group consisted of four to six participants. Focus group data were collected from the same centers where directors were interviewed. Teachers were informed that all information shared during focus groups was confidential, and directors were not present at teacher focus groups. Like individual director interviews, teachers were provided with CACFP fact sheets that outlined updates to the nutrition guidelines. Teachers were asked questions related to the facilitators of and barriers to implementing CACFP requirements. Additionally, topics covered during teacher focus groups included other policies implemented at the program level, supports for and challenges to promoting healthy habits, as well as resources needed for and recommendations to implement nutritional guidelines. Focus groups were conducted at the teachers' respective ECE program location and lasted for approximately 60 minutes.

\section{Data Analysis}

Qualitative data were analyzed using a thematic analysis (Braun \& Clarke, 2006) process facilitated by computer-assisted qualitative analysis software, NVivo10. The thematic analysis included transcribing, coding, and the development of themes (Stemler, 2001). Our research team reviewed transcripts of the focus groups and semi-structured interviews. Researchers engaged in systematic analysis required for intercoder reliability. Transcripts were then independently coded using a priori codes based on the topics that were covered in the interview protocol (Stemler, 2001). Before coding, all members of the research team met to review the a priori codes and to add any additional codes based on topics that came up during the interviews (Paulus, 2014). During initial rounds of coding, emergent codes were flagged so that they could be discussed with the research team.

Further, differences in coding were investigated and identified during team meetings where questions on separating or merging certain codes, and code segment boundaries were discussed. As a result, agreements on defining and demarcating codes, categories, and subsequent 
themes were reached, leading to observed results. After comparison and consensus of coding were completed, memoing was used to develop and refine themes (Braun \& Clarke, 2006).

\section{RESULTS}

The following results present the findings from the thematic analysis. A total of four dominant themes related to healthy food and beverage policy implementation were developed: (1) "It lists everything about the daycare": ECE Programs rely on handbooks to guide program policies.

(2) ECE directors and teachers describe implementing healthy food and beverage policies as "kind of easy."

(3) "Parents that aren't willing to tell their kids no": Key barriers to implementing healthy food and beverage policies.

(4) ECE teachers provided recommendations to improve the implementation of nutrition policies. Furthermore, eight sub-themes emerged related to key facilitators of and critical barriers to healthy food and beverage policy implementation. The findings are arranged within the dominant themes and are supported by direct quotes from participants.

\section{"It lists everything about the daycare": ECE programs rely on handbooks to guide program policies}

ECE programs are not required to participate in CACFP; however, due to state licensing regulations in Georgia and CACFP prominence, most ECE program directors are aware of CACFP guidelines. When ECE directors were asked about the policies that guided their program, they often referred to policies in the form of handbooks. These handbooks range from 8 to 70 pages. They include information related to nutrition guidelines, rules about not bringing outside or homemade food into the ECE program, expectations for student behavior (e.g., politeness), schedules for ECE activities, and as one director noted:

"The procedures when you're doing registration for children with food allergies" (Director Interview).

Another director shared how ECE center policies are shared via handbooks and the information they provide:

"I have a handbook that the parents get. It's about eight, nine pages. And it lists everything about the daycare: what time to arrive. [...] It has my schedules on what time we eat, and talks a little bit about nutrition. And you know, if their child has a food allergy, what we do. What I expect the parents to help do, cause there's some things that become extremely expensive" (Director Interview).

The handbooks, according to the directors, are vital to communicating the policies, rules, and nutrition guidelines that dictate the ECE program's daily operations, decision-making, and activities. While directors perceived the handbooks as essential tools to share program policies, they also recognized that not all parents read the handbook. For example, a director reported:

\section{"They [parents] understand it better when you tell them; then they're not going to read the handbook. We've had that issue" (Director Interview).}

Because of this, many of the directors reinforce the policy information provided in the handbook via oral communication, newsletters/handouts, and electronic communication (e.g., blogs, emails).

\section{ECE directors and teachers describe implementing healthy food and beverage policies as "kind of easy"}

During the interviews and focus groups, participants discussed how CACFP guidelines were "very easy" to implement in their respective programs, especially the procedures that promote drinking water and eating fruits and vegetables. Participants further explained how they used interactive food activities to expand the children's palates and support their healthy eating habits as well as the key resources they perceived most helpful to support their implementation of nutrition policies. These findings reveal participants' perceptions of healthy food and beverage policies and provide concrete examples of facilitators used to implement them. Further details about these findings are presented as subthemes below.

\section{ECE Programs' Ability to Make Water Easily Accessible}

CACFP guidelines require that water is available inside and outside for self-serve for children. Program directors and teachers found this guideline easy to implement. For instance, one teacher described how easy it is for the center to provide water to children, mainly when they are thirsty from playing outside. She explained:

"Water, when you serve it inside and outside, it's kind of easy. Especially if they're [children] out running, playing, they'll refresh" (Teacher Focus Group).

Another teacher reported how serving water to children is easy due to the accessibility of water fountains in the ECE classrooms.
"They have water fountains in their classroom so that their kids are able to go to the water fountain when they want to and things like that" (Teacher Focus Group)

Other ways ECE programs make water accessible to the children they serve include the use of water pitchers and 
water bottles. In terms of pitchers, one ECE director reported:

"I have two jugs of water downstairs. And it's available all through the day to make water readily available for the children" (Director Interview).

An ECE director described how the children at her center have access to water bottles or "little coolers" to encourage water intake. She reported:

"We bought medium sized little coolers that they could actually take out on the playground with them. So that the kids have access to water anytime on the playground that they wanted" (Director Interview).

Building on Children's Fondness for Fruits and Vegetables Program directors and teachers reported most fruits and vegetables are easy to serve because the majority of the children genuinely enjoy eating them. Participants shared that "most kids like basic fruit, pineapples, apples" and "eat a ton of fruits and vegetables.” One director explained:

"Serving fruits or vegetables" is like "serving snacks" to the children" (Director Interview)

Because of the children's positive response to fruits and vegetables, implementing this aspect of the policy is "very easy," according to participants. Yet, participants also acknowledged that children were mainly fond of the fruits and vegetables that are familiar to them. Therefore, interactive activities are provided to introduce children to a broader range of fruits and vegetables.

\section{Interactive Food Activities}

Directors and teachers shared five different interactive food activities they provided to encourage more pleasurable food experiences and healthy habits among the children they serve. The first, taking field trips to the farm to enhance children's knowledge of and interaction with different fruits and vegetables. The second, working with children in a garden, which, in turn, further encouraged the children to eat healthy foods. A director referenced gardening as an interactive way to engage children:

"They eat the little cherry tomatoes because we grew them” (Director Interview).

The third, taking children on a picnic or having them enjoy "sack lunches" outside to enhance the experience of eating healthy foods. The fourth, mixing vegetables into recipes. A director indicated one way to encourage vegetable intake:

"[We can put ]..whole vegetables into a half a cup of water and some ice to make a smoothie" (Director Interview).
And the fifth, providing condiments to augment children's enjoyment of eating fruits and vegetables. Although providing condiments is not an activity per se, one director shared:

"They [the children] love dipping their vegetables in ranch dressing and pouring dressing over their salads" (Director Interview)

Resources that support nutrition policy implementation Directors and teachers were asked to describe specific types of resources used to facilitate children's healthy habits. Participants shared resources from the federal government, such as the USDA MyPlate materials, which were particularly useful. These materials, most often in the form of posters depicting the "MyPlate" or a plate and cup divided into sections for each food group (fruit, vegetables, protein, grains, and dairy), were perceived as beneficial to reinforce the nutritional guidelines. One director described how she used the MyPlate materials at her center. She noted:

"When we set up dramatic play, we put the little MyPlate in laminate and put it on the table... And then we talk to the children about what they're eating-if it's healthy. So we do that..." (Director Interview).

In addition to USDA materials, a few of the program directors and teachers discussed how parents are considered a resource. Parents helped with meal planning, providing advice on how to prepare certain foods for their children, and different foods to try with children.

While not all program directors reported working with a professional, some directors discussed the advice they received from professionals as a valuable resource to implement healthy foods and beverages policies at their centers. Most notably, directors relied on nutritionists for support. One director shared:

"I brought in a nutritionist and she did a workshop for parents. Only a few parents attended the workshop so I brought in a team that came in and talked about health and safety: when to keep your child home. That was a big hit with parents" (Director Interview).

Another director shared:

"[We have] professional nutritionists work on menus. The nutritionist provides an eight-week sample schedule that we can implement" (Director Interview).

Another professional mentioned during the director interviews stated: 
"A "feeding therapist" is an excellent resource for information for getting kids to ... appreciate the food. The smell. The taste" (Director Interview).

A technical assistant, a CACFP corporate person, staff at the Special Supplemental Nutrition Program for Women, Infants, and Children (WIC), and required nutrition training sessions were mentioned as significant resources as well. One ECE director noted:

"So we use parents as a resource. We use our CACFP corporate person as a resource. Also, because of the area that we're in, sometimes, we can use the people from the WIC office as resources. They're willing to come out and educate parents, especially when it comes to the milk and all that kind of stuff. What age is proper to have this kind of milk versus this kind of milk" (Director Interview).

Another ECE Director noted the use of professionals to assist with learning health information and policies:

"With Georgia Resources for Children... I have a TA, a Technical Assistant. She comes by every three months. We also have to go to a class once a year. We have to go to a class that tells us what's new, and what has changed, and what we need to do. So, with her coming by and with my red book [from class], it kind of keeps me in line" (Director Interview).

"Parents that aren't willing to tell their kids no": Key barriers to the implementation of their healthy food and beverage policies

ECE program directors and teachers perceived some parents as barriers to implementing healthy food and beverage policies. A few parents, according to participants, did not consistently promote healthy eating nor limit their children's SSB intake at home. Because of this, directors and teachers reported challenges related to limiting SSBs, and encouraging "picky eaters" to try something new was challenging. In addition, program directors shared concerns regarding the high cost of serving healthy foods. These issues are further discussed across the four sub-themes presented below.

Inconsistent Habits Between Home and School

Overall, both ECE program directors and teachers shared that while the ECE program may promote healthy eating habits, these habits have no consistent enforcement when children are at home with their parents. One teacher discussed the challenge this way:

"I would say the challenge would be school and home because here, they get fruits, vegetables.
They get a full meal that they're supposed to have” (Teacher Focus Group).

As mentioned in the "It lists everything about the daycare": ECE programs rely on handbooks to guide program policies theme, as part of their healthy food and beverage policies, ECE programs reported that they do not allow outside food in their centers. However, directors and teachers reported some parents going against center rules, bringing unhealthy food into the ECE programs, which was perceived as a major challenge. Participants shared parents tend to provide unhealthy food options that their children enjoy, rather than encourage healthier food choices. One teacher shared:

"It's the big one [challenge] with the parents. It's parents that aren't willing to tell their kids, 'No... We can't bring that in here [ECE center]", (Teacher Focus Group).

Another teacher explained the issue of some parents wanting to bring outside food into the center this way:

"The parents are not used to what the school system says. So they think that they should be allowed to bring in outside food for special occasions" (Teacher Focus Group).

Challenges with Limiting Juice Intake

Although ECE programs try to limit children's juice intake based on policy guidelines, doing so was perceived as particularly difficult because parents did not consistently limit their child's juice intake at home. Similar to some parents sending their children to centers with unhealthy food, some parents sent their children to the center with sweetened juice. Participants shared that parents did not perceive juice to be a highly sweetened beverage. Because of this, participants had to regularly "inform" parents about the high sugar content of most juice beverages. One director shared:

"I think that one of the biggest problems and struggles that we have is juice. Parents like juice. They send in cups with juice. If I had to say there was one problem that we have, it was probably we don't do juice more than once a week on our menu. Sometimes not at all. We prefer fresh fruits and vegetables as opposed to the juice component. I think that's probably my biggest struggle is informing parents about the sugar content of juice, and why juice isn't necessarily healthy like they think" (Director Interview).

Participants further noted:

"Trying to get them [children] away from the juice a lot can be a little hard because they're so 
used to getting juice at home" (Director Interview).

A teacher shared the tension between the children's desire for juice drinks and healthy beverage guidelines when she stated:

"They [children] want more juice. But they just can't have more juice" (Teacher Focus Group).

Challenges with Encouraging Picky Eaters to Try Something New

While many children enjoyed fruits and vegetables, teacher focus group participants discussed issues with encouraging some children to try unfamiliar food. Specifically, this issue involves children not liking the texture of or refusing to eat specific fruits and vegetables. For example, teachers mentioned the challenges they face when getting children to eat food they find unappetizing. One teacher's comment illustrates this challenge:

"When I first started here, she (an infant) did not like baby food. She was only...like ten months. She wouldn't touch it. She would gag and make herself throw up. To this day, she still has a thing about texture" (Teacher Focus Group).

Another teacher reported the following about children who refuse "to try something new":

"Our problems are more with the picky eaters. The good eaters, they're good and they will eat and they understand. And you can tell their parents have that dialogue. But then you've got the ones that just won't. And I can only do so much as an educator to be like, 'Okay, just try to eat it.' I can't physically make them open their mouth and try it. So it just makes it hard for them to be willing to try something new" (Teacher Focus Group).

Similar to the findings of the Inconsistent Habits Across Home and School theme, participants noted how parents with picky eaters tend to provide food options that their children enjoy and/or are familiar to them, rather than continuously encourage experimentation with different healthy food choices.

\section{Concerns about Food Costs}

Interviews with ECE directors revealed challenges related to the cost of serving healthy food. Directors shared their perspectives about "pricey" food items:

"I think cost is a big one [challenge]. Providing as much fruit as we do, it's hard. It's [fresh fruit] more expensive in the wintertime, you know. So we're limited in resources when choosing to serve] canned or fresh [fruit]. In the wintertime, of course, it's canned. I mean fruit, when it's not in season, it's aggravating. You can't. You want to serve it, and you're paying a lot of money for fruit when it's not in season" (Director Interview).

As the new CACFP guidelines require new provisions for reimbursement. A director expressed concerns with the cost of healthy foods stating:

"The aspect of leaner proteins, moving away from processed foods. And just because of time and cost issues, that would probably be the biggest [challenge]" (Director Interview).

Another director agreed with concerns about the cost of healthy foods indicating a need to buy fruits in season:

"We're not going to be crazy and do something out of season, you know. Right? Watermelons in January. Right. \$20 watermelon or something. But on occasion, I would love to do organic apples in Ellijay, which isn't that far. So I'm like, you all couldn't just chuck that a little cheaper?" (Director Interview).

\section{ECE Teachers Provided Guidance on Ways to Improve Nutrition Policy Implementation}

ECE directors and teachers were asked for suggestions to support programs implementing healthy food and beverage policies. Participants indicated that programs needed to make eating healthy food and beverages more engaging for children. Table 1 presents teacher recommendations to improve nutrition policy implementation. 
Table 1

Georgia ECE Teacher Recommendations to Improve Nutrition Policy Implementation as Reported in Statewide Focus Groups and Interviews

\begin{tabular}{|c|c|c|}
\hline Recommendation & Description & Supportive Quote from ECE Teachers \\
\hline $\begin{array}{l}\text { 1. Connect healthy } \\
\text { eating to the curriculum } \\
\text { lessons }\end{array}$ & $\begin{array}{l}\text { Teachers identified a need to } \\
\text { incorporate the promotion of } \\
\text { healthy foods in a variety of ways } \\
\text { through daily lessons. }\end{array}$ & $\begin{array}{l}\text { "Like if I serve just a sandwich, what I try to do is initiate what we're } \\
\text { learning into the food. If we're doing the triangle, I cut the sandwich in a } \\
\text { triangle and ask them [the children], 'What shapes do you see on your } \\
\text { plate?" (Director Interview). }\end{array}$ \\
\hline $\begin{array}{l}\text { 2. Use more interactive } \\
\text { activities to engage } \\
\text { children in healthy } \\
\text { eating habits }\end{array}$ & $\begin{array}{l}\text { Teachers described ways to involve } \\
\text { children in exciting, hands-on } \\
\text { activities related to healthy eating. }\end{array}$ & $\begin{array}{l}\text { "Getting the kids to do more projects, ...like more hands-on projects with } \\
\text { food and implementing more cooking classes throughout...or anything } \\
\text { that has the kids involved" (Director Interview). }\end{array}$ \\
\hline $\begin{array}{l}\text { 3. Adhere to written } \\
\text { ECE program policies }\end{array}$ & $\begin{array}{l}\text { Teachers explained the importance } \\
\text { of maintaining and enforcing } \\
\text { written policies related to healthy } \\
\text { eating. }\end{array}$ & $\begin{array}{l}\text { "If you have to have a policy, stick by it. If we have our policy written, and } \\
\text { this is what we say, then that's how we mean it. You have to stick by it" } \\
\text { (Director Interview). }\end{array}$ \\
\hline $\begin{array}{l}\text { 4. Pursue learning } \\
\text { opportunities to learn } \\
\text { about nutrition policy } \\
\text { changes }\end{array}$ & $\begin{array}{l}\text { Teachers discussed the importance } \\
\text { of professional development in the } \\
\text { area of nutrition. }\end{array}$ & $\begin{array}{l}\text { "Teachers need to seek more "conferences" to learn about policy } \\
\text { changes" (Director Interview). }\end{array}$ \\
\hline $\begin{array}{l}\text { 5. Implement policy } \\
\text { changes in increments to } \\
\text { gain support from } \\
\text { parents, teachers, and } \\
\text { children. }\end{array}$ & $\begin{array}{l}\text { Teachers described an incremental } \\
\text { period to introduce and implement } \\
\text { nutrition policies to increase buy-in } \\
\text { and adherence to program policies. }\end{array}$ & $\begin{array}{l}\text { "Implement [policy] changes slowly...over time so that kids don't start to } \\
\text { really notice things disappearing. Parents don't start to notice things } \\
\text { disappearing. And then you're set to where you should be" (Director } \\
\text { Interview). }\end{array}$ \\
\hline $\begin{array}{l}\text { 6. Explore ways to raise } \\
\text { funds to subsidize costs } \\
\text { of healthy foods }\end{array}$ & $\begin{array}{l}\text { Teachers expressed the need to find } \\
\text { ways to decrease the cost of healthy } \\
\text { foods. }\end{array}$ & $\begin{array}{l}\text { "Incorporate the cost [of healthy foods and beverages] into the tuition..." } \\
\text { (Director Interview). }\end{array}$ \\
\hline
\end{tabular}

\section{DISCUSSION}

The current study aimed to learn more about barriers and facilitators to the implementation of food and beverage policies in the ECE setting. The directors were asked to share their perspectives on nutrition policies, how these policies are implemented, and challenges faced during implementation. The center directors reported two primary resources they used to facilitate healthy nutrition policies: 1) federal government materials (e.g., USDA materials), and 2) 
advice from professionals (e.g., dietitians, lactation specialists). Other studies, however, have noted that there is a vital need to provide ECE teachers with credible nutrition resources (Sharma et al., 2013). Nutrition knowledge varies greatly among ECE teachers, and most have not received formal nutrition education or training (Sharma et al., 2013). Therefore, ensuring that ECE teachers are aware of reliable resources is critical. The key facilitators to meeting nutrition policies were the ability to make water easily accessible, the children's fondness of fruits and vegetables, and the availability of interactive and engaging resources. By having water fountains or child-friendly pitchers and cups in the classrooms, ECE teachers found it easy to implement the policy of having water readily available to the children. These findings are different from the outcome of a Connecticut study that showed while most classrooms had access to water, many of them only had adult-accessible faucets rather than child-accessible fountains (Middleton et al., 2013). ECE professionals also reported that serving fruits and vegetables was made easier by the children's general fondness of fruits and vegetables, especially ones that are familiar. In other studies, factors such as taste, food preparation methods, and teacher modeling affect whether or not some children are willing to eat certain foods (Sisson et al., 2017). Addressing these factors can make children more likely to consume fruits and vegetables (Sisson et al., 2017).

This study identified several barriers to implementing nutrition policies and guidelines. One of the issues that emerged was effectively communicating the center guidelines to parents of attending children. While handbooks were the most common method centers used to document and communicate their nutrition policies with families, not all parents read the manual. Inconsistent habits between school and home were a reported barrier. In like manner, a survey of ECE teachers in Oklahoma indicated that teachers feel there is a lack of consistency in behaviors, guidelines, and expectations between the ECE center and the children's homes (Sisson et al., 2017). Lack of consistent promotion of healthy habits is a problem because children learn many of their nutrition and physical activity habits from their parents (Nezami et al., 2016). If parents are not implementing the same healthy practices as an ECE program, children will have less exposure to those habits and may be less likely to adopt them. Lastly, the cost of healthy foods was an issue of concern at many ECE centers, particularly during the off-season months for fruits and vegetables. Food costs are a widespread concern and barrier reported by many ECE centers (Carroll et al., 2011). Findings from this study and others implemented in the United States show that ECE teachers experience similar barriers to implementing healthy food and beverage policies.

One study limitation is that qualitative data was conducted with ECE professionals in Georgia and may not be generalizable to other states. However, this study does have many strengths. Pertinent to this special issue on Research Translation to Community Transformation, the present study specifically engaged the community at the start of the research process to inform the future intervention development and study design. The use of a community-engaged approach provided invaluable insight from ECE directors and teachers to yield solutions to barriers to the implementation of healthy eating practices in ECE setting. Our research aimed to capture the perspectives of ECE teachers across the state, including all ECE program types, as well as CACFP participating and non-CACFP participating programs. Study findings will help fill the gaps in knowledge concerning facilitators and barriers to adopting healthy food and beverage policies in the ECE setting. Obtaining a better understanding of these facilitators and barriers will assist with future policy design and implementation.

\section{CONCLUSIONS}

Children start to develop food habits and behaviors at a very young age (Brown et al., 2015). Improving the implementation of nutrition policies in the ECE setting may assist children in adopting healthy habits early in life. ECE teachers are role models for healthy eating habits. Using qualitative methodology allowed our research team to elucidate the needs of ECE teachers to effectively implement nutrition policies. Public health professionals can employ findings as they develop resources, training, and programs related to nutrition policy implementation in the ECE setting.

\footnotetext{
Acknowledgements

This research was supported by grant \# 74373 from the Robert Wood Johnson Foundation through its Healthy Eating Research program. The authors would greatly appreciate the ECE professionals who participated in their study, without whom this research would not be possible. The authors are sincerely grateful for the support and assistance provided by the Georgia Department of Early Care and Learning. We honor the legacy and life of Dr. Leann Birch, an imminent scholar, mentor, and friend. The authors also thank the undergraduate and graduate students in the Childhood Obesity Laboratory at the University of Georgia for their assistance in data collection and data entry.

\section{References}

Benjamin-Neelon S.E., Vaughn A.E., Tovar A., Østbye T., Mazzucca S., Ward D.S. The family child care home environment and children's diet quality. Appetite, 2018, (126):108-13.

Bethell C., Read D., Goodman E., Johnson J., Besl J., Cooper J., et al. Consistently Inconsistent: A Snapshot of Across- and Within-State Disparities in the Prevalence of Childhood Overweight and Obesity. Pediatrics, 2009, 123 (Supplement 5): S277-S286.

Brown C.L., Halvorson E.E., Cohen G.M., Lazorick S., Skelton J.A. Addressing childhood obesity: opportunities for prevention. Pediatric Clinics of North America, 2015, 62(5):1241-61.

Budd G.M, Hayman L.L. Childhood obesity - Determinants, prevention, and treatment. Journal of Cardiovascular Nursing. 2006, 21(6):437-41.
} 
Braun V., and Clarke V. Using thematic analysis in psychology. Qual Res Psychol. 2006; (3): 77-101.

Carroll J., Demment M., Stiles S., Devine C., Dollahite J., Sobal J., Olson C. Overcoming Barriers to Vegetable Consumption by Preschool Children: A Child Care Center Buying Club. Journal of Hunger \& Environmental Nutrition, 2011, 6(2):153-165.

Choy C., Isong I.A. Assessing preschoolers' beverage consumption using the theory of planned behavior. Clinical Pediatrics, 2018, 57(6):711-21.

Cotwright C.J., Bales D.W., Lee J.S., Parrott K., Celestin N., Olubajo B. Like Peas and Carrots: Combining Wellness Policy Implementation with Classroom Education for Obesity Prevention in the Childcare Setting. Public Health Reports, 2017, (132):74S-80S.

Cotwright, CJ, Bradley, H, Celestin, N, Drake, S, Love, K, Birch, L (2019). Beverage Policy Implementation by Child and Adult Care Food Program Participation and Program Type: A Statewide Examination in Georgia. Childhood Obesity, 2019, 15 (3): 185-193.

Creswell J.W. Research design. In: Research Design Qualitative, Quantitative, and Mixed

Methods Approaches. Second. Thousand Oaks: SAGE Publications; 2003. p. 1-26.

Dev D.A., McBride B.A., Speirs K.E., Blitch K.A., Williams N.A. "Great Job Cleaning Your Plate Today!" Determinants of Child-Care Providers' Use of Controlling Feeding Practices: An Exploratory Examination. Journal of the Academy of Nutrition and Dietetics, 2016, 116(11): 1803-9.

Hales C.M., Carroll M.D., Fryar C.D., Ogden C.L. Prevalence of obesity among adults and youth: United States, 2015-2016. National Center for Health Statistics data brief, 2017, (288): 1-7.

Hales C.M., Fryar C.D., Carroll M.D., Freedman D.S., Ogden C.L. Trends in Obesity and Severe Obesity Prevalence in US Youth and Adults by Sex and Age, 2007-2008 to 2015-2016. Journal of the American Medical Association, 2018, 319 (16):1723-5.

Ickes M., McMullen J., Haider T., Sharma M. Global School-Based Childhood Obesity Interventions: A Review. International Journal of Environmental Research and Public Health, 2014, (9): 8940.

Lott M., Callahan E., Welker Duffy E., Story M. Daniels S. Healthy Beverage Consumption in Early Childhood: Recommendations from Key National Health and Nutrition Organizations. Consensus Statement.

http://healthyeatingresearch.org. Published 2019. Accessed February 20, 2020.

Middleton A.E., Henderson K.E., Schwartz M.B. From Policy to Practice: Implementation of Water Policies in Child Care Centers in Connecticut. Journal of Nutrition Education and Behavior, 2013, 45(2):119-125.

Namenek Brouwer R.J., Benjamin Neelon S.E. Watch Me Grow: A garden-based pilot intervention to increase vegetable and fruit intake in preschoolers. BMC Public Health, 2013, 13(1):1-6.

Natale R.A., Lopez-Mitnik G., Uhlhorn S.B., Asfour L., Messiah S.E. Effect of a child care center- based obesity prevention program on body mass index and nutrition practices among preschool-aged children. Health Promotion Practice, 2014, 15(5):695-705.

Nayak K., Hunter K., Owens J., Harrington J. Nutritional Assessment of Snacks and Beverages in Southeastern Virginia Daycare Centers. Clinical Pediatrics, 2018, 57(4):410-6.

Paulus T, Lester J, Deptster P. Digital Tools for Qualitative Research. Los Angeles, CA: SAGE Publications; 2014.

Ritchie L.D., Boyle M., Chandran K., Spector P., Whaley S.E., James P., et al. Participation in the Child and Adult Care Food Program is associated with more nutritious foods and beverages in child care. Child Obes. 2012;8:224-9.

Sharma S., Dortch K.S., Williams C.B., Truxilio J.B., Rahman G.A., Bonsu P., Hoelscher D. Nutrition-related Knowledge, Attitudes, and Dietary Behaviors among Head Start Teachers in Texas: A Cross-sectional Study. Journal of the Academy of Nutrition and Dietetics, 2013, 13(4):558-562.

Sisson S.B., Smith C.L., Cheney M. Big Impact on Small Children: Child-Care Providers' Perceptions on Their Role in Early Childhood Healthy Lifestyle Behaviours. Child Care in Practice, 2017, 23(2):162-180.

Robert Wood Johnson Foundation. 2019. "State of Childhood Obesity."

https://media.stateofobesity.org/wp-content/uploads/2019/11/18 171114/SoCo-Report-WEB-111819.pdf. Accessed February 20, 2020.

Stemler S. An overview of content analysis. Practical Assessment, Research \& Evaluation. 2001;7:1-6.

Story M., Kaphingst K.M., French S. The Role of Child Care Settings in Obesity Prevention. The Future of Children, 2006, 16(1):143-168.

Swift J.A., Tischler, V. Qualitative Research in Nutrition and Dietetics: Getting Started. Journal of Human Nutrition \& Dietetics, 2010, 23(6):559-66.

United States Department of Agriculture. Child and Adult Care Food Program: Meal pattern revisions related to the Healthy, Hunger-Free Kids Act of 2010.

https://www.gpo.gov/fdsys/pkg/FR-2016-04-25/pdf/2016-09412 .pdf. Published 2016. Accessed February 20, 2020.

U.S. Department of Health and Human Services. Dietary Guidelines for Americans 2015-2020 Eight Edition. https://health.gov/sites/default/files/2019-09/2015-2020_Dietary Guidelines.pdf. Published December 2015. Accessed February 20, 2020.

Vall E.A, Kibbe D.L, O'Connor J.C, Greene C., Smith K.S. Leading the Way in Preventing Childhood Obesity in Georgia. Public Health Reports. 2017; 132:3S-6S.

Witt K.E., Dunn C. Increasing Fruit and Vegetable Consumption among Preschoolers: Evaluation of Color Me Healthy. Journal of Nutrition Education and Behavior, 2012, 44(2):107-13.

Zhai F., Raver C.C., Li-Grining C. Classroom-based interventions and teachers' perceived job stressors and confidence: Evidence from a randomized trial in Head Start settings. Early Childhood Research Quarterly, 2011, 26(4):442-52. 